\title{
Polarimetric Radar Observations at Low Levels during Tornado Life Cycles in a Small Sample of Classic Southern Plains Supercells*
}

\author{
Matthew S. Van Den Broeke and Jerry M. Straka \\ School of Meteorology, University of Oklahoma, Norman, Oklahoma
}

ERIK N. RASMUSSEN

Rasmussen Systems, Mesa, Colorado

(Manuscript received 7 February 2007, in final form 20 July 2007)

\begin{abstract}
Preliminary schematics of polarimetric signatures at low levels in southern plains classic supercells are developed for pretornado, tornado, and tornado demise times from a small collection of cases, most of which are cyclic tornado producers. Characteristic signatures and patterns are identified for the reflectivity factor $\left(Z_{\mathrm{HH}}\right)$, the differential reflectivity $\left(Z_{\mathrm{DR}}\right)$, the correlation coefficient $\left(\rho_{\mathrm{hv}}\right)$, and the specific differential phase $\left(K_{\mathrm{DP}}\right)$. Signatures likely related to an ongoing tornado are also discussed. Major findings in $Z_{\mathrm{HH}}$ at tornado times include "wings" of higher values often extending away from the updraft region, a stronger gradient on the west side of the echo appendage, and a local maximum at the storm location favorable for tornadogenesis. Increasing cyclonic curvature of the hook-echo region was noted through the tornado life cycle. The $Z_{\mathrm{DR}}$ tended to indicate hail shafts most commonly at tornado times, with the highest storm values typically located along the storm's forward flank throughout the tornado life cycle. A $Z_{\mathrm{DR}}$ minimum often occurred at the tornado-favorable location, while low $Z_{\mathrm{DR}}$ occasionally trailed the tornado region. Stormminimum $\rho_{\mathrm{hv}}$ typically occurred at the tornado-favorable location at tornado times and in hail shafts or heavy rain areas at other times. Another region of low correlation was the storm updraft, while the highest storm correlation was typically found in the downwind light-precipitation shield. The $K_{\mathrm{DP}}$ typically exhibited a storm-core temporal maximum at tornado times, with the highest storm values in regions of hail and heavy rain and the lowest values in the downwind light-precipitation region. Values in the tornadofavorable region were typically near zero and sometimes strongly negative.
\end{abstract}

\section{Introduction and motivation}

Supercell thunderstorms cause much damage and significant loss of life, especially on the Great Plains of the central and south-central United States. These longlived convective storms produce numerous hazardous weather phenomena, most notably very heavy rain, large hail, damaging straight-line wind, and tornadoes. Nearly all long-lived tornadoes, and almost all strong-

* Supplemental information related to this paper is available at the Journals Online Web site: http://dx.doi.org/10.1175/ 2007JAMC1714.s1.

Corresponding author address: Jerry M. Straka, 120 David L. Boren Blvd., Suite 5900, Norman, OK 73072.

E-mail: jstraka@ou.edu to-violent tornadoes, are produced by supercell thunderstorms.

Much research has been published containing conceptual models of supercell structures using radar reflectivity. A multilayer conceptual model was first presented by Browning (1965; Fig. 1a) that showed the evolution of the hook echo based on storms that struck the Oklahoma City, Oklahoma, region. Lemon (1977) presented a supercell model that showed the reflectivity structure in two and three dimensions, including a core of highest reflectivity just downwind from the cyclonically rotating primary updraft and rear-flank downdraft (the mesocyclone), an echo appendage extending south and southwest from this region as precipitation wraps around the intensifying mesocyclone, and decreasing reflectivity downwind from the primary updraft. (Here, "downwind" is defined as the direction in which a storm feature embedded in the usually westerly midlevel 
(a)

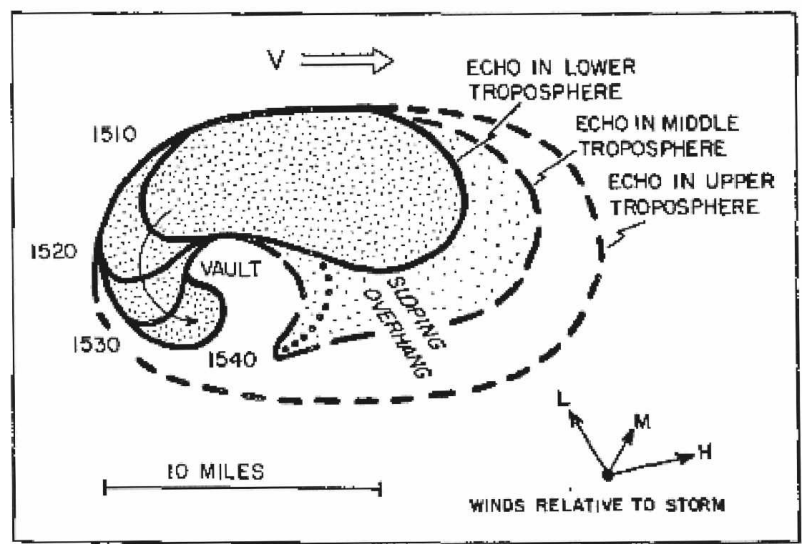

(b)

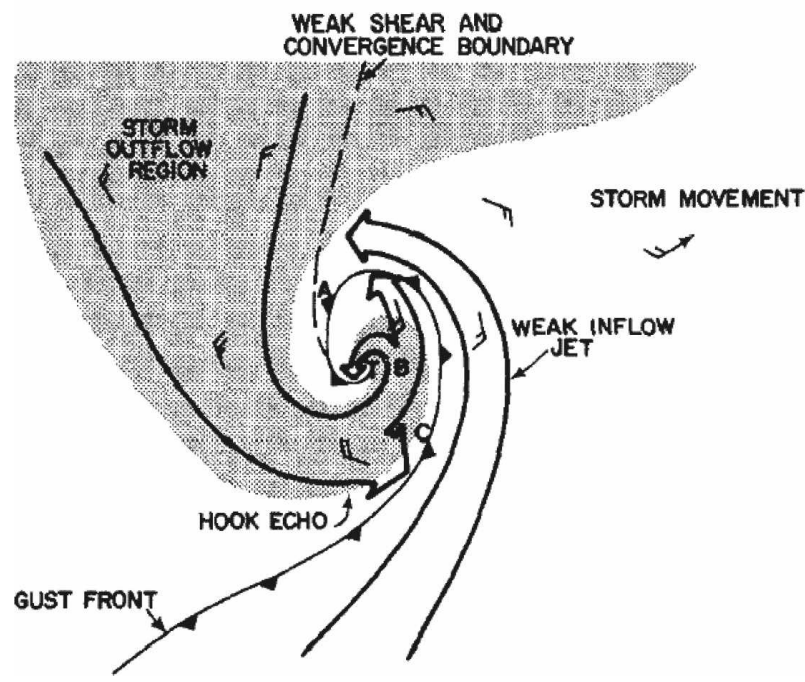

FIG. 1. (a) The Browning (1965) model of supercell storm characteristics at three levels, and hook-echo evolution. The tornado occurs on the inside of the circulation producing the hook echo. (b) The Brandes (1978) model of low-level mesocyclone structure and characteristics while a tornado is ongoing. Features noted by Brandes include a tornado $(\mathrm{T})$, primary storm updraft (A), downdraft within the mesocyclone's core or occlusion downdraft (B), and possible location of a gust-front tornado (C). Full wind barbs represent $10 \mathrm{~m} \mathrm{~s}^{-1}$; half-barbs represent 5 $\mathrm{m} \mathrm{s}^{-1}$. (c) The 1979 structural model of a tornadic supercell published by Lemon and Doswell (1979). Features noted include the updraft (UD), FFD, RFD, and T. Radar-echo boundaries are encompassed by the thick line. Frontal symbols denote the gust-front and "occlusion" structure of the storm. Streamlines are ground relative. (d) Tornadic-region characteristics of the 20 May 1977 Del City-Edmond supercell through the tornado life cycle, presented by Brandes (1981). Arrows represent storm-relative low-level streamlines; hatched areas represent rainy downdraft; stippled areas represent regions of high vertical vorticity associated with the updraft. The region of high radar reflectivity is outlined in black, and gust-front location is indicated by a dashed line. The I denotes a region of upper-level dry air at the pretornado time, while RDD represents the rear-flank downdraft. The black dot in stages $b$, c, and d represents the tornado location. (c)

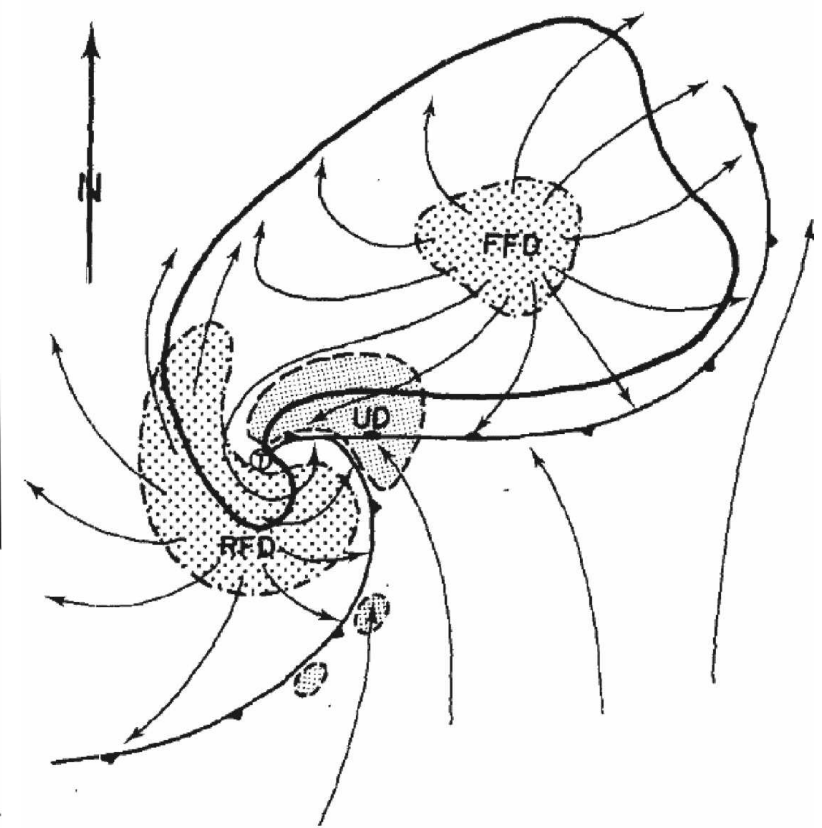

(d)

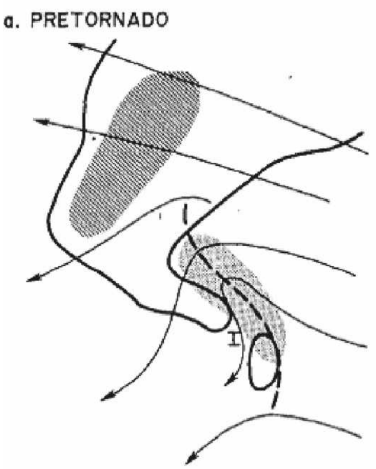

b. TORNADOGENESIS

c. MATURE STAGGE
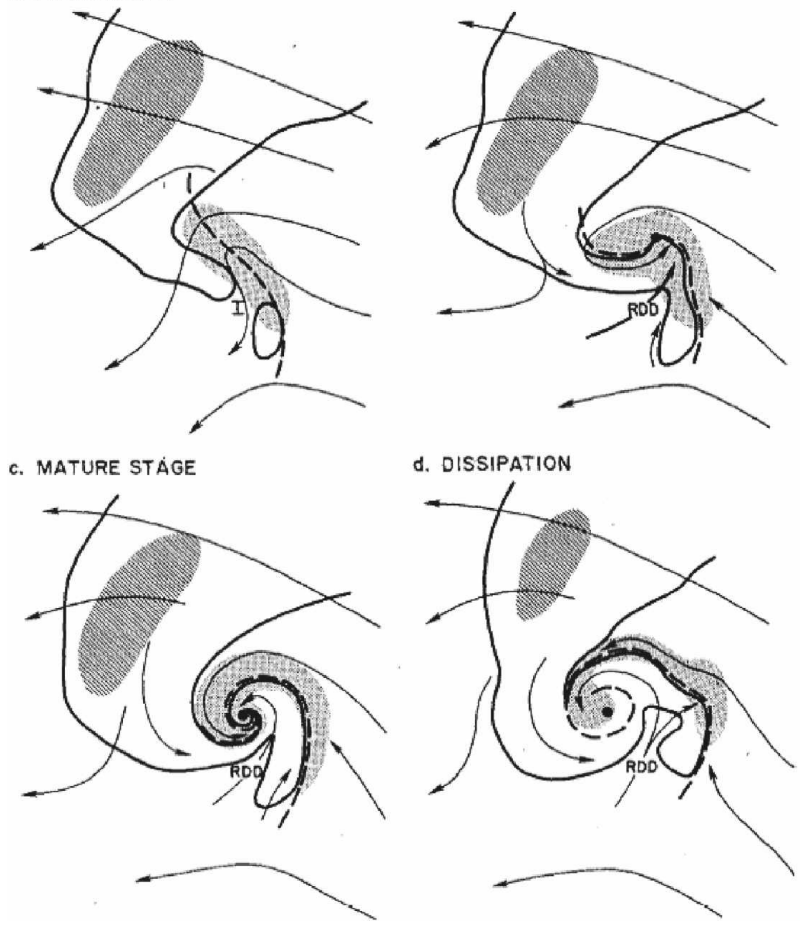
storm-relative flow would move by advection to an eastward location being viewed from the south.) Reflectivity in this downwind precipitation region often exhibits extended areas of high values, giving the supercell a "winged" appearance. The mechanism producing this appearance remains unknown.

Brandes (1978) published a conceptual model of lowlevel mesocyclone structure during the tornadic phase (Fig. 1b). His model shows a well-defined echo appendage with storm inflow curving into the tornado region from the southeast and east. In Brandes's model, the tornado is typically located at the tip of the hook echo or inside the tip of the hook.

Lemon and Doswell (1979) presented a modified conceptual model of a tornado-producing supercell thunderstorm (Fig. 1c). Some additional features of this model include forward- and rear-flank downdrafts (FFD and RFD, respectively) and a flanking line of convection. The forward-flank downdraft forms downwind (eastward) from the mesocyclone under the supercell's precipitation shield, while the rear-flank downdraft forms within the echo appendage (see also Markowski 2002). A flanking line of convection, typically extending southwest from the storm and often marked by young developing cells, indicates the leading edge of RFD-associated outflow.

Brandes (1981) examined supercell structural evolution through the tornado life cycle. His Fig. 10 (shown here as Fig. 1d) shows a region of dry upper-level air intruding on the southwest side of the storm at the pretornado time, under which a rear-flank downdraft develops near the time of tornadogenesis. The swirling component of the low-level flow is at maximum during the mature stage. By the time of tornado dissipation in our diagrams (shown later), the storm updrafts and mesocyclones have considerably diminished because of a lack of fresh, buoyant air from the low-level inflow. A new updraft might form downstream from the previous updraft and the tornado cyclone and tornadogenesis process might begin again, as occurred in many of the cases referenced herein.

Under different environmental conditions, different types of supercells are known to form. Moller et al. (1994) published the first unified description of the supercell spectrum. Rasmussen and Straka (1998) attributed some of this variability to the role of upper-level storm-relative flow in redistributing hydrometeors. Storms utilized in developing the schematics herein were classic supercells (Moller et al. 1994).

Despite much work conceptualizing supercell structure (e.g., Doswell and Burgess 1993), this problem has not been approached from the perspective of polarimetric radar. The most significant work thus far using polarimetric data is by Ryzhkov et al. (2005), in which some very preliminary polarimetric patterns are observed in a few tornadic supercells, along with some interpretations.

Dual-polarization Doppler radar, in which electromagnetic waves are transmitted and received with both horizontal and vertical polarization, yields additional information to that provided by single-polarization radars. Polarimetric data can be used to infer ongoing microphysical processes within storms via a hydrometeor classification algorithm (HCA; e.g., Straka 1996; Straka et al. 2000) and offer great promise for learning more about supercell structure. However, no unified polarimetric schematics of supercells have yet been published or produced to the knowledge of the authors. Thus, the goal of the current study is to develop preliminary low-level, or approximately base-scan level, polarimetric schematics of tornadic supercells on the southern plains for four of the most commonly used polarimetric variables $\left(Z_{\mathrm{HH}}, Z_{\mathrm{DR}}, K_{\mathrm{DP}}\right.$, and $\left.\rho_{\mathrm{hv}}\right)$. In cases from the Cimarron dual-polarimetric Doppler radar (CIM), only two variables are examined $\left(Z_{\mathrm{HH}}\right.$ and $\left.Z_{\mathrm{DR}}\right)$.

A unified polarimetric schematic of supercell thunderstorms is needed because of the expected upgrade of the current Weather Surveillance Radar-1988 Doppler (WSR-88D) network to polarimetric capability starting around 2009 or 2010 (D. Zrnić 2006, personal communication). National Weather Service (NWS) and private sector forecasters looking at these data will benefit by knowledge of supercell polarimetric signatures and changes in the polarimetric variables through the supercell life cycle. Nowcasters may be able to more accurately identify specific severe weather threats with the storms, especially the presence of large hail and tornadoes, primarily utilizing $Z_{\mathrm{HH}}, Z_{\mathrm{DR}}, K_{\mathrm{DP}}$, and $\rho_{\mathrm{hv}}-$ the available variables on the polarimetric WSR-88Ds (D. Zrnić 2006, personal communication).

Our dataset is limited because of the dearth of tornadic supercells observed with polarimetric radar (seven storms on the southern plains of which we are aware), which provides the basis for preliminary lowlevel polarimetric schematics of these types of storms. As the sample size is small, care must be taken to not overgeneralize our results. As dual-polarization capability is installed in the WSR-88D radars in forthcoming years, a more definitive climatology of signatures will likely emerge, much as it did for reflectivity from the 1960 s to 2000 .

In section 2 we explain our definitions and describe the methodology. Schematics for the southern plains are presented in section 3. Concluding remarks and future research are discussed in section 4. 


\section{Terminology and methodology}

Datasets used include tornadic supercell cases collected by the Cimarron and Norman (KOUN) dualpolarimetric Doppler radars. CIM (no longer operational) was located about $40 \mathrm{~km}$ west-northwest of Norman, Oklahoma, and KOUN is located in Norman. Details on the Cimarron radar can be found in Zahrai and Zrnić (1993). Information about KOUN can be found in Zrnić and Ryzhkov (1999) and Doviak et al. (2000, 2002).

Low-level data were examined for this study; the low levels were defined as the lowest- elevation angle available at each time of interest. When the lowest-elevation scan was considerably contaminated by ground clutter near a supercell/tornado or the supercell/tornado was very close to the radar $(<15 \mathrm{~km})$, the next-higher scan was used.

In the present study, seven storm cases were taken from central Oklahoma, all of which produced tornadoes cyclically. Schematics developed from these cases might also apply to the southern plains regions of eastern and central Texas, the Texas and Oklahoma Panhandles, and eastern Kansas. It has been found in general that southern plains cases differ in some regards from high plains cases, presumably because southern plains supercells are generally "warm based" (cloudbase temperatures of $T>15^{\circ} \mathrm{C}$ ), while high plains supercells are generally "cold based" (cloud-base temperatures of $T<5^{\circ} \mathrm{C}$ ), though there are exceptions. Unfortunately, perhaps because climatology favors fewer tornadoes on the high plains, thus far data have only been collected from three high plains supercell tornado cases that the authors are aware of. Preliminary schematics of these are not presented herein because of the small sample size, but they will be discussed in a forthcoming paper. Many similarities exist among high plains storms, which are quite different from southern plains storms.

Preliminary schematics developed in the present study are divided into pretornado, tornado, and tornado demise times. The pretornado time was defined as approximately 12 to $15 \mathrm{~min}$ before the initial tornado report, and was taken from the one to three low-level scans nearest this criterion. Tornado times were defined as those at which a tornado was reported to be occurring by an observer. These were chosen based both on the observations of scientists viewing the storms and on the Storm Prediction Center (SPC)'s storm report database. Tornado times reported in the SPC database were found to be biased approximately 8 min late, although this bias may be less in central Oklahoma (D. Burgess 2007, personal communication). Be-
TABLE 1. Dates and sum number of times (volumes) of PTT, TT, and TDT used for this study of southern plains storms.

\begin{tabular}{lc}
\hline \multicolumn{1}{c}{ Date } & No. of volumes \\
\hline 13 Jun 1998 & 12 \\
5 Oct 1998 & 12 \\
3 May 1999 & 14 \\
8 May 2003 & 16 \\
9 May 2003 & 25 \\
24 May 2004 & 04 \\
29 May 2004 & 30 \\
\hline
\end{tabular}

cause of the potential bias, caution was used in defining tornado times from the SPC tornado reports. Many storms used in this study produced well-known and well-documented tornadoes (e.g., storms on 3 May 1999 and 8-9 May and 9-10 May 2003), which aided in assuring the accuracy of chosen tornado times. A tornado demise time was defined as the time of the low-level radar scan temporally nearest observed tornado dissipation. Case dates and number of volume or sector scans used in the current study are presented in Table 1. For each polarimetric variable at each time of interest, notes and schematic drawings were constructed, allowing compilation of the repeatable patterns worthy of being reported herein. As only one previous study has looked at polarimetric data of supercell tornadoes (Ryzhkov et al. 2005), comparisons are frequently made to these findings.

Regions of high $(\mathrm{H})$, medium $(\mathrm{M})$, and low $(\mathrm{L})$ values were delineated for each variable in each case. Many of the high, medium, and low values were chosen based on thresholds presented in Straka et al. (2000), while others were defined based on observational experience. After ranges of variables were delineated, preliminary schematic drawings were created for the southern plains at pretornado (PTT), tornado (TT), and tornado demise (TDT) times for each polarimetric variable. On these schematics, regions of $\mathrm{H}, \mathrm{M}$, and $\mathrm{L}$ values are denoted, as well as areas denoted $\mathrm{V}$, where variability between cases was too great for a conclusion to be drawn about typical values. A denotation of $\mathrm{V}$ in a region of a supercell schematic does not mean the region is completely devoid of a somewhat repeatable pattern. Here, $\mathrm{V}(\mathrm{M} / \mathrm{L})$ means the area is primarily a mix of medium and low values, while $\mathrm{V}(\mathrm{H} / \mathrm{M})$ means the area is primarily a mix of high and medium values. There were places without repeatable patterns, which are indicated as $\mathrm{V}(\mathrm{H} / \mathrm{M} / \mathrm{L})$. A bold supercell outline on the schematic drawings approximately represents the 20- $\mathrm{dB} Z$ reflectivity contour for the composite storm. In the text, "schematic storm" refers to the preliminary schematic drawing made for a given time period and polarimetric variable. 
Preliminary schematics were constructed such that repeatable, noted features were placed relative to the storm's updraft region. In future studies, further quantification of these results may be helpful.

It is also important to note that these schematics were developed from data of cyclically tornadic supercells. Fewer nontornadic cases exist, which were not examined during the development of the schematics presented herein. Therefore, caution is advised when interpreting these schematics in the context of the tornado life cycle. More nontornadic cases need to occur and be analyzed relative to the tornadic cases before strong conclusions can be reached about the differences between tornadic and nontornadic storms, and before we can state how robust the apparently tornadoindicative signatures actually are.

\section{Dual-polarimetric schematics at low levels for tornadic supercells}

In this section we develop low-level, dual-polarimetric southern plains schematics of tornadic supercells for four of the most commonly used polarimetric variables.

\section{a. Reflectivity $Z_{H H}$}

Reflectivity $\left(Z_{\mathrm{HH}}\right)$ is the component of radar energy both transmitted and received with horizontal polarization, and it is familiar from the current WSR-88D network. This variable represents reflection of a radar signal from hydrometeors and nonmeteorological scatterers. For further discussion and caveats of this variable, see Doviak and Zrnić (1993), Straka et al. (2000), or Bringi and Chandrasekar (2001). An example of $Z_{\mathrm{HH}}$ data used to construct the schematics herein is presented in Fig. 2. Others are shown in the supplementary material provided in an appendix online.

\section{1) Pretornado times}

A well-defined hook echo was frequently found at pretornado times, although it was often wider and less cyclonically curved than at either tornado or tornado demise times (Figs. 2, 3). At pretornado times, reflectivity $>50 \mathrm{~dB} Z$ was observed to cover much more of the spatial area of the echo appendage than at tornado times. A well-defined echo appendage, which is present at all of the times studied in the supercell life cycle, was not found useful in distinguishing whether a supercell was in the process of producing a tornado, but it may appear more cyclonically curved while a tornado was ongoing or dissipating (Figs. 2,3). The presence of the hook echo, however, seemed quite useful in indicating the presence of a maturing or well-developed mesocyclone (e.g., Forbes 1981; Markowski 2002).

In addition, the descending reflectivity core (DRC; Rasmussen et al. 2006) was also frequently found in the echo appendages. The location of these at the times considered is indicated on the reflectivity schematics with a circle. The circle's size corresponds to the approximate size of the DRC central region (Fig. 3), though the size of the DRC depends on the reflectivity threshold used to define it. While a study by Rasmussen et al. (2006) found that isolated tornadic supercells generally had a DRC, a more comprehensive climatology by Kennedy et al. (2007) showed the occurrence of a DRC with isolated tornadic supercell storms to be less frequent. Because of these studies we felt compelled to indicate where this feature might be found. Though the DRC is not shown with a reflectivity maximum in the schematics, if one were to occur, reflectivity would be at least $4 \mathrm{~dB}$ greater than in the surrounding hook echo (and not resolved by the reflectivity-mapping thresholds used in this paper). An increase in reflectivity in the DRC relative to the surrounding hook-echo reflectivity could be much more than $4 \mathrm{~dB}$ (Kennedy et al. 2007; Rasmussen et al. 2006).

Reflectivity maxima along the southern and northern storm flanks were significantly less frequent and less well defined than in the later tornado stages. Maximum reflectivity was typically concentrated just downstream from the primary storm updraft. The reflectivity gradient at the back edge of the echo appendage was typically not as strong as at tornado times, at least in the preliminary schematics developed from this sample of storms (Figs. 2, 3).

\section{2) Tornado times}

During times of an ongoing tornado, a well-defined hook echo was usually present, with high values of $Z_{\mathrm{HH}}$ $(>50 \mathrm{dBZ})$ often extending south into the echo appendage (Figs. 2,3). The appendage was typically thinner than at pretornado times and often possessed greater cyclonic curvature. A sharp reflectivity gradient, seen more often than at pretornado times, was frequently located at its back (western) edge. Highest storm reflectivity at low levels was typically located downwind from the primary updraft and extended northeast along the storm's forward flank. Secondary maxima in reflectivity extended northeast from this region along the storm's northern flank, giving the reflectivity pattern a winged or a butterfly appearance.

A cyclonic-anticyclonic rotational couplet at the tip of some echo appendages, identified by reflectivity showing paired vortices curling about their rotational centers, was frequent at tornado times (an example can 

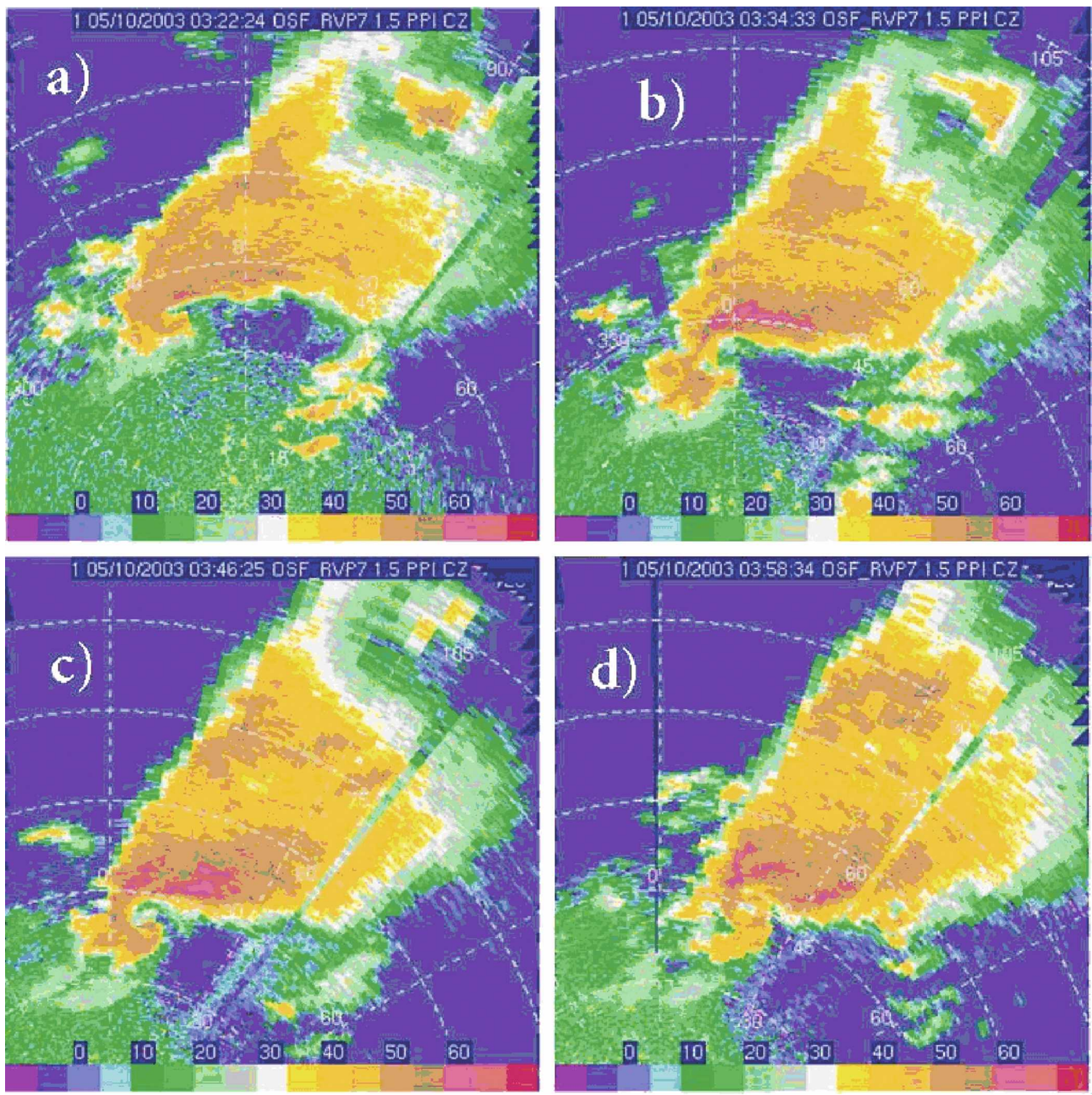

FIG. 2. Progression of reflectivity factor $\left(Z_{\mathrm{HH}}\right)$ through a tornado life cycle in the 9-10 May 2003 supercell, which produced an F3 tornado during this time. Represented are (a) the pretornado time, (b) an earlier tornado time, (c) a later tornado time, and (d) the tornado demise time.

be seen in Fig. 5b of the supplemental appendix available online). This feature was not observed during any pretornado or tornado demise times in the current study and seems indicative of a supercell in the tornadic phase. During tornado times, regions of high reflectivity often extended prominently to the northeast away from the primary storm updraft region (Figs. 2, 3).

It is believed that a reflectivity maximum associated with a tornado might occur, as debris are lofted and reflects energy back to the radar (Burgess et al. 2002; Ryzhkov et al. 2005). Care must be taken as noted above, since this reflectivity maximum could represent the newly discovered DRC described by Rasmussen et al. (2006). DRCs can be identified as descendingreflectivity patterns in a series of PPI scans in the vertical or three-dimensional images of storm reflectivity. In addition, they occur prior to tornadogenesis and therefore would not be associated with debris.

\section{3) ToRnAdo DEMISE TIMES}

At demise times, the supercell hook-echo region tended to exhibit more cyclonic curvature than at any other time (Fig. 3). Perhaps this occurs because the hook echo and tornado are wrapped around the meso- 

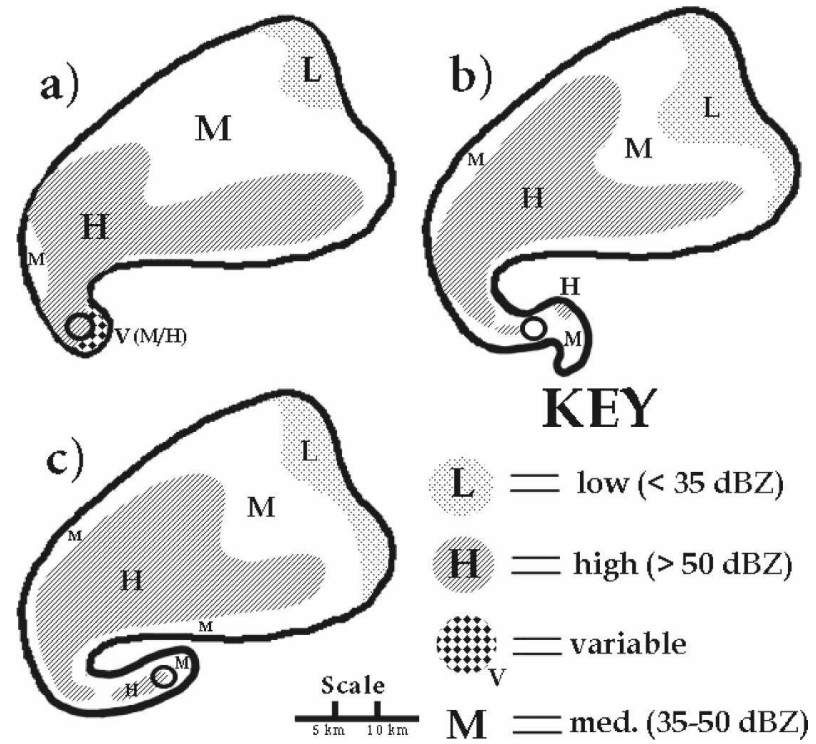

FIG. 3. Schematics of reflectivity factor $\left(Z_{\mathrm{HH}}\right)$ for the southern plains at (a) pretornado times, (b) tornado times, and (c) tornado demise times. Stippled areas represent low values $\left(Z_{\mathrm{HH}}<35\right.$ $\mathrm{dBZ})$, hatched areas represent high values $\left(Z_{\mathrm{HH}}>50 \mathrm{dBZ}\right)$, blank areas represent intermediate values $\left(35 \mathrm{~dB} Z \leq Z_{\mathrm{HH}} \leq 50\right.$ $\mathrm{dB} Z$ ), and checkerboard-filled areas represent variable regions. Thick outline represents approximately the $20-\mathrm{dB} Z$ reflectivity contour.

cyclone, sometimes into the body of the storm (Fig. 3). Highest storm $Z_{\mathrm{HH}}$ was typically located just downstream from the primary updraft, as expected, although a relatively thin filament of high values $(>55 \mathrm{dBZ})$ often extended well south into the hook echo. Detached regions of high reflectivity were often found even farther away from the main storm body in the hook echo (i.e., typically farther south).

Wings of high $Z_{\mathrm{HH}}$ extending east and northeast from the updraft were sometimes visible at tornado demise times but were usually not as prominent a feature as at tornado times. Also, at tornado demise times, the back of the supercell (typically its west side) tended to exhibit a lesser reflectivity gradient than at tornado times. A maximum $Z_{\mathrm{HH}}$ gradient at the back of the storm was observed while a tornado was ongoing (Figs. $2,3)$.

\section{b. Differential reflectivity}

Differential reflectivity $\left(Z_{\mathrm{DR}}\right)$ is 10 times the base-10 logarithm of the ratio of the horizontal- to verticalreflectivity factor. Thus, it is a measure of how much horizontally polarized energy is reflected compared to the reflection of vertically polarized energy, and it gives an estimate of the oblateness or prolateness of hydrometeors in the sample volume. This variable has shown significant usefulness in hail detection (Herzegh and
Jameson 1992; Doviak and Zrnić 1993; Straka 1996; Straka et al. 2000; Bringi and Chandrasekar 2001) and has real-time tornado-recognition potential (Ryzhkov et al. 2005). An example of $Z_{\mathrm{DR}}$ data used to construct the schematics herein is presented in Fig. 4.

\section{1) Pretornado times}

Near-zero $Z_{\mathrm{DR}}$ collocated with high reflectivity was used to infer the presence of low-level hail shafts in the supercells studied (Straka 1996; Straka et al. 2000). At pretornado times, this hail signature occurred much less frequently than at tornado times (Figs. 4, 5). Medium values (1-2 dB) often covered a larger area of the echo appendage and extended more continuously to join a large area of medium values typically located on the northwest side of the schematic storm. High-forwardflank $Z_{\mathrm{DR}}$ was present, and well-defined inflow maxima, although slightly less frequent, were about as common as at tornado times (Figs. 4, 5).

\section{2) TornAdo TIMES}

A hail shaft, inferred from collocated high $Z_{\mathrm{HH}}$ and low $Z_{\mathrm{DR}}$, was identified in the lowest-available elevation angle more often at tornado times than at pretornado times (Figs. 4, 5). This implied hail shaft was most frequently located just downstream from the primary updraft, in a location favored for the fallout of hail (Moller et al. 1994). One might speculate that this pattern change describes a storm updraft beginning to collapse during the tornadogenesis and tornado stages. This speculation is discussed further in a companion paper.

Forward-flank values of differential reflectivity were high in nearly all tornado and pretornado cases examined, with values typically exceeding $2-3 \mathrm{~dB}$ in this region (Figs. 4, 5). Values of $Z_{\mathrm{DR}}$ this high can indicate a few large, oblate raindrops, especially when reflectivity is not high (Straka et al. 2000). The forward flank tends to be an area of inflow and updraft, and the presence of high $Z_{\mathrm{DR}}$ in this region implies ongoing drop sorting (Ryzhkov et al. 2005). Larger drops are able to fall against storm inflow, while smaller drops are advected into the storm. Thus, a region of sorted larger drops is expected to develop along the storm's forward flank, leading to the observed high $Z_{\mathrm{DR}}$.

A well-defined differential reflectivity inflow maximum, the base of a column of high $Z_{\mathrm{DR}}$, was present at a slightly greater percentage of tornado times than pretornado times, but the relatively small difference was not thought significant. The hook-echo region typically contained medium values of $Z_{\mathrm{DR}}(1-2 \mathrm{~dB})$, though larger values were not uncommon (Figs. 4,5).

Ryzhkov et al. (2005) observe the occasional pres- 

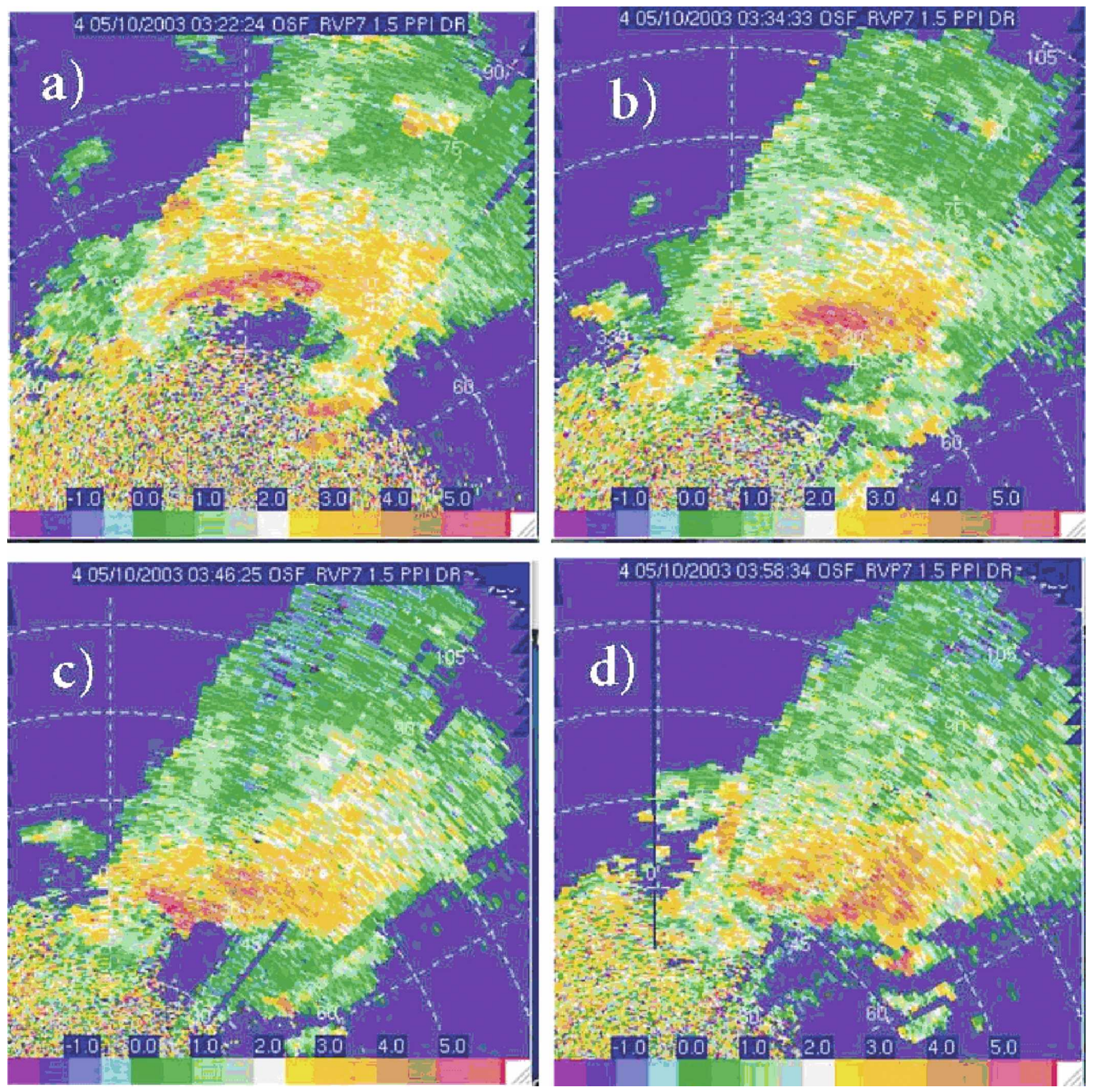

FIG. 4. As in Fig. 2, but for differential reflectivity $\left(Z_{\mathrm{DR}}\right)$.

ence of comma-shaped areas of high $Z_{\mathrm{DR}}$ in the supercell inflow region. This pattern has been attributed to a centrifuging effect of the low-level mesocyclone, causing larger drops to move outward in cyclonically curved bands. It could also indicate storm inflow bands containing large drops. These bands of large drops would be visible to a radar operator as cyclonically curved bands of high $Z_{\mathrm{DR}}$. Such curved bands were not prevalent but did occur in several of the tornado cases examined (see the online supplemental appendix material of actual radar data used to construct the schematics herein).

As discussed in Herzegh and Jameson (1992), $Z_{\mathrm{DR}}$ can exhibit low values near the tip of the hook echo if a tornado is present, since tumbling debris behave much the same as large hail in that it tends to tumble randomly and present roughly equal horizontal and vertical surface areas to a scanning radar. Ryzhkov et al. (2005) define a $Z_{\mathrm{DR}}$ debris signature as a pixel containing $45 \mathrm{dBZ}<Z_{\mathrm{HH}}<55 \mathrm{dBZ}$ and $Z_{\mathrm{DR}}<0.5 \mathrm{~dB}$. Such a signature was indeed found in at least 9 of the 12 southern plains tornado cases examined, and this signature was thought to be a good indicator of an ongoing tornado. One case even exhibited the $Z_{\mathrm{DR}}$ debris signature when the tornadic region was approximately 100 $\mathrm{km}$ from the radar, perhaps (depending on the radar beam path and therefore on atmospheric conditions) indicating a rather tall and wide debris column. This 


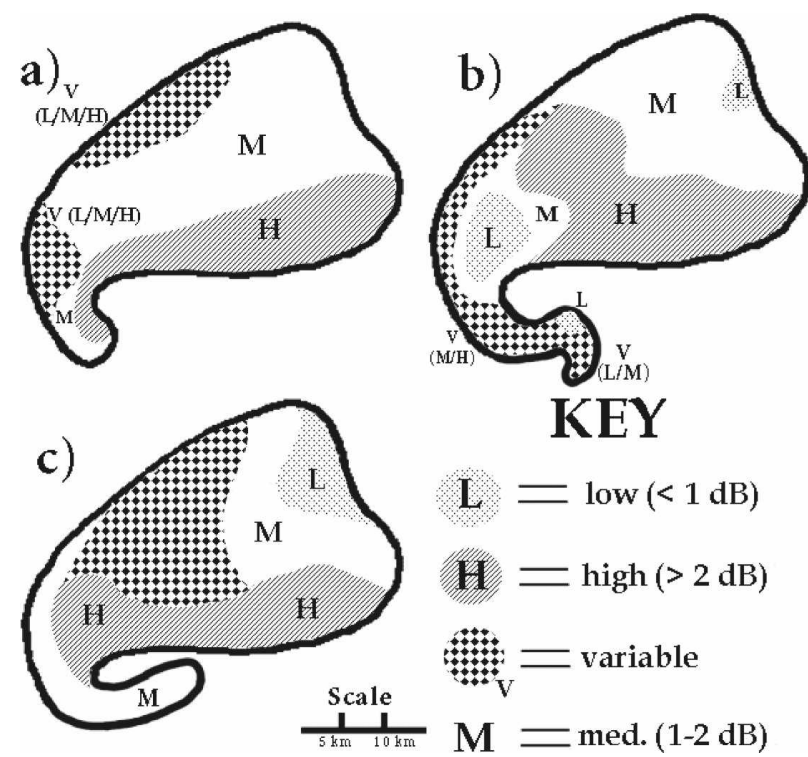

FIG. 5. As in Fig. 3, but for differential reflectivity $\left(Z_{\mathrm{DR}}\right)$. Stippled areas represent low values $\left(Z_{\mathrm{DR}}<1 \mathrm{~dB}\right)$, hatched areas represent high values $\left(Z_{\mathrm{DR}}>2 \mathrm{~dB}\right)$, blank areas represent intermediate values ( $\left.1 \mathrm{~dB} \leq Z_{\mathrm{DR}} \leq 2 \mathrm{~dB}\right)$, and checkerboard-filled areas represent variable regions. Thick outline represents approximately the $20-\mathrm{dB} Z$ reflectivity contour.

signature must be used with caution, since differential attenuation of the horizontally and vertically polarized signals could result in local $Z_{\mathrm{DR}}$ minima not associated with tornadic debris. Therefore, confidence in an ongoing tornado is increased when additional tornadoindicative signatures are also present. Lower $Z_{\mathrm{DR}}$ has been known to trail the tornadic region as lofted debris are left behind (Ryzhkov et al. 2005).

\section{3) Tornado DEMise times}

For reasons discussed above, high $Z_{\mathrm{DR}}(>2 \mathrm{~dB})$ was again located along the forward flank (Figs. 4 and 5) of the schematic storm, with medium values $(1-2 \mathrm{~dB})$ typically just downwind from this region. Low- $Z_{\mathrm{DR}}$ regions in the storm core, collocated with high $Z_{\mathrm{HH}}$ and associated with hail shafts, occurred in a few cases but typically were not large or well defined and sometimes were not present at all.

Extended regions of higher $Z_{\mathrm{DR}}$ to the east in the main storm were often present but were not typically as well defined (Fig. 5) as at earlier times. In the hookecho region, $Z_{\mathrm{DR}}$ values typically were medium (1-2 $\mathrm{dB}$ ) but could exhibit large regions with low values, perhaps indicating the presence of residual tornadolofted debris.

\section{c. Correlation coefficient}

The correlation coefficient $\left(\rho_{\mathrm{hv}}\right)$ is a measure of the correlation between the horizontally and vertically re- turned radar signals at zero lag. Many factors affect the correlation, such as the presence of particle mixtures, the distribution of hydrometeor orientations, and the irregularity of particle shapes (Straka et al. 2000). Randomly tumbling irregular particles, for instance, would have low values of $\rho_{\mathrm{hv}}$. This polarimetric variable has been found useful in hail and tornado detection (Ryzhkov et al. 2005). The $\rho_{\mathrm{hv}}$ data from the Cimarron radar were used with caution, since a signal-processing error caused $\rho_{\mathrm{hv}}$ to be negatively biased. Thus these data allowed use only for a relative comparison of values, even though the absolute magnitude of values is not correct (Ryzhkov et al. 2005). For these reasons the data are not shown. For further discussion of the correlation coefficient, see Doviak and Zrnić (1993), Straka et al. (2000), and Bringi and Chandrasekar (2001). An example of $\rho_{\mathrm{hv}}$ data used to construct the schematics herein is presented in Fig. 7, discussed below.

\section{1) Pretornado times}

Low $\rho_{\mathrm{hv}}(<0.95)$ was typically associated with the storm's hail shaft, if one was present. Nearly all of the cases with a hail shaft identified by collocated high $Z_{\mathrm{HH}}$ and low $Z_{\mathrm{DR}}$ also had low $\rho_{\mathrm{hv}}$ in the same location, typically just downstream from the primary updraft. Since hail shafts were found to be more prevalent using $Z_{\mathrm{HH}}$ and $Z_{\mathrm{DR}}$ at tornado times than at pretornado times, the presence of an area of low $\rho_{\mathrm{hv}}$ associated with large hail was less frequent at pretornado times (Figs. 6, 7).

Low $\rho_{\mathrm{hv}}$ values, though higher than those found in hail shafts, occurred with heavy rain as identified by collocated high $Z_{\mathrm{HH}}$ and $Z_{\mathrm{DR}}$ (Straka et al. 2000). Typical values of $\rho_{\mathrm{hv}}$ in heavy rain were $0.95-0.98$. These values could also be found in mixtures of rain and hail. The location of this signature was consistent with the theory of supercell structure, typically downstream from and surrounding the hail region (Figs. 6, 7).

Highest low-level storm $\rho_{\text {hv }}$, typically $>0.98$ and ranging up to $\sim 1$ (perfect correlation between horizontal and vertical signals), was usually located in the large light-precipitation region of the supercell, far downwind from the primary updraft (Fig. 7). In this region, reflectivity typically was also low ( $<40 \mathrm{~dB} Z)$, indicating lighter rain. Lighter rainfall is often composed of relatively spherical droplets (Jameson and Beard 1982), allowing correlation to be high (Straka et al. 2000).

\section{2) Tornado times}

Composite storms at tornado times were not easily distinguishable from their pretornadic counterparts by $\rho_{\text {hv }}$. The hail and heavy rain regions, denoted by low 

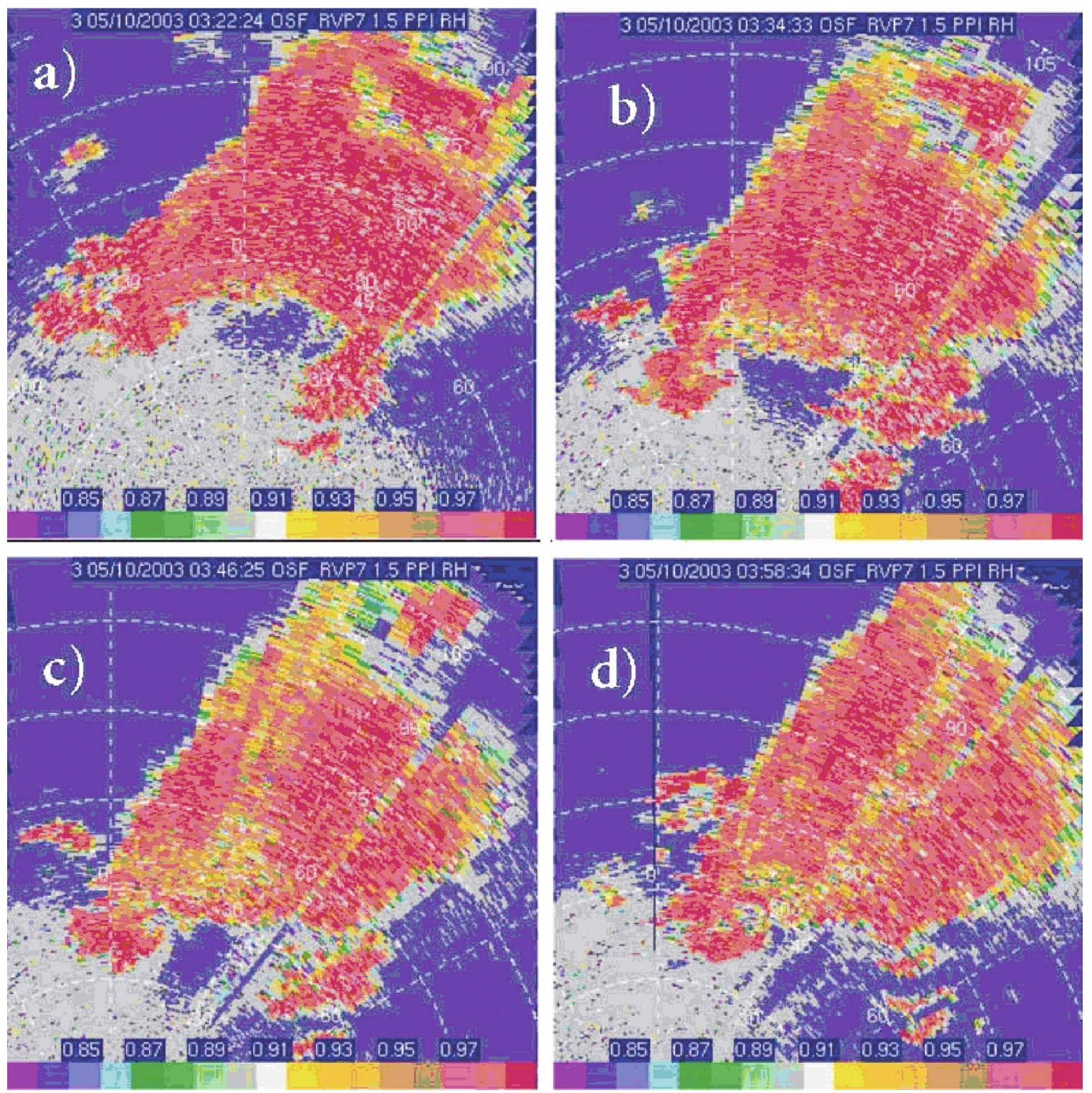

FIG. 6. As in Fig. 2, but for the correlation coefficient $\left(\rho_{\mathrm{hv}}\right)$.

correlation, were in approximately the same locations (Figs. 6,7). Since a hail shaft was found to be more common at tornado times, this low-correlation signature was more prevalent at tornado times. The region of high $\rho_{\text {hv }}$ collocated with light rain may have been slightly larger.

Outside the large hail and heavy rain regions, another area of low $\rho_{\mathrm{hv}}$ was the updraft itself. Ryzhkov et al. (2005) note that $\rho_{\mathrm{hv}}$ will be low in the updraft when strong inflow produces a mixture of raindrops and light debris such as leaves and grass. Such a depression of $\rho_{\mathrm{hv}}$ was seen in nearly all tornado cases examined. Ryzhkov et al. suggest the magnitude of the $\rho_{\mathrm{hv}}$ depression and its vertical extent might be useful as a means of evaluating updraft strength.

Low $\rho_{\mathrm{hv}}$ is theorized to occur with the tornado vortex, since the horizontally and vertically received signals in tumbling, randomly shaped debris and particles will not be closely related. Ryzhkov et al. (2005) define a $\rho_{\mathrm{hv}}$ debris signature as a pixel containing $45 \mathrm{dBZ}<Z_{\mathrm{HH}}<$ $55 \mathrm{dBZ}$ and $\rho_{\mathrm{hv}}<0.8$. For the Cimarron cases, since a signal-processing error affected $\rho_{\mathrm{hv}}$ values, this threshold was lowered to 0.6 . Such a signature was found in the supercell's tornado-favorable location in several of the tornado cases examined. In most cases, this region contained the lowest $\rho_{\mathrm{hv}}$ in the entire supercell, usually 


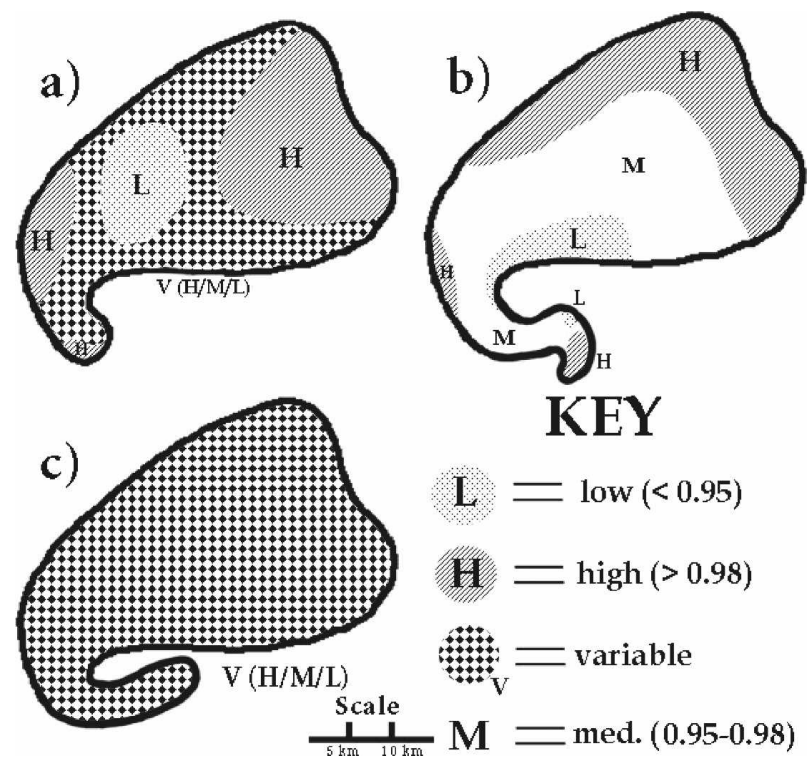

FIG. 7. As in Fig. 3, but for the correlation coefficient $\left(\rho_{\mathrm{hv}}\right)$. Stippled areas represent low values $\left(\rho_{\mathrm{hv}}<0.95\right)$, hatched areas represent high values $\left(\rho_{\mathrm{hv}}>0.98\right)$, blank areas represent intermediate values $\left(0.95 \leq \rho_{\mathrm{hv}} \leq 0.98\right)$, and checkerboard-filled areas represent variable regions. Thick outline represents approximately the $20-\mathrm{dB} Z$ reflectivity contour.

$<0.75$ and sometimes $\leq 0.4$. Values as low as 0.2 have even been reported from the raw radar data in the 8 May 2003 tornado case (Ryzhkov et al. 2005). Worthy of note, two cases not exhibiting such a signature were the two most distant from the radar ( $>70 \mathrm{~km}$ away), so the radar beam may have passed above any debris column. It is theorized that the $\rho_{\mathrm{hv}}$ debris signature will not be as prevalent if the tornado is moving over an area of low debris availability and if the tornado is weaker. Ryzhkov et al. (2005) indicate a lower strength limit of $\mathrm{F} 3$ for this and other polarimetric tornado signatures to be well defined, although we hypothesize the existence of a spectrum of tornado signature strengths rather than the presence or absence of such signatures. Another necessary consideration is the typically shorter life of weaker tornadoes, inferred by their much shorter average pathlengths (Brooks 2004); a tornado with a short life is less likely to be sampled.

\section{3) ToRnAdo DEMISE TIMES}

Major differences existed between the cases in all supercell regions, so the composite storm was completely designated as having high variability (Fig. 7). A majority of cases, however, did contain lower $\rho_{\mathrm{hv}}$ just downwind from the primary updraft in the region favored for hail and large raindrops, as seen previously (Fig. 6). More data would have to be obtained to ascertain whether an anomalous case, which had high val- ues $(>0.98)$ in the same region, was representative of some supercells going through tornado demise or if it was truly an outlier.

\section{4) Supercell wake Region}

Ryzhkov et al. (2005) define the supercell "wake" signature as an area trailing a supercell with $Z_{\mathrm{HH}}<30$ $\mathrm{dB} Z, \rho_{\mathrm{hv}}<0.7$, and average $Z_{\mathrm{DR}}$ between 1 and $2 \mathrm{~dB}$. They attribute this signature to the residual presence of light debris lofted in the supercell's wind field. (The reader is referred to their paper for an excellent discussion of why lofted debris is the most likely source of the supercell wake signature.) Tornadic debris could result in such a signature, as could any other light debris that could be lofted by even a nontornadic storm (e.g., grass or leaves). Of our tornado cases, two strongly exhibited this signature, while two additional cases only marginally exhibited it (Fig. 8). Three negative cases were distant from the radar $(>70 \mathrm{~km}$; including the 24 May 2004 storm, which only produced weak, short-lived tornadoes), and the region of the wake signature would have been even more distant and behind the storm. It is speculated that the presence of such a signature is probably difficult at best to ascertain when the storm is distant $(>60 \mathrm{~km})$ from the radar. We speculate that the supercell wake signature would increase following a tornado, or following an increase in the near-storm wind field. It may be useful to investigate potential operational significance of this signature.

\section{d. Specific differential phase}

Specific differential phase $\left(K_{\mathrm{DP}}\right)$ is a local measure of phase shift caused by a radar beam's interception of scatterers, causing a change in the phase angle of the transmitted signal's electric field vector. Each transmitted signal polarization is scattered differently by a given collection of hydrometeors (unless all are spherical), so the change in phase angle will vary among different signal polarizations. This differential phase change is measured by the radar as $\phi_{\mathrm{DP}}$, the differential phase shift. From $\phi_{\mathrm{DP}}, K_{\mathrm{DP}}$ is calculated by taking the difference of $\phi_{\mathrm{DP}}$ over a given range. Greater liquid water content and anisotropy of scatterers produce greater differential phase shifts and therefore higher $K_{\mathrm{DP}}$ values. This variable is potentially useful in determining the presence of hail and can be helpful in raising nowcasters' confidence in the presence of an ongoing tornado. Unfortunately, $K_{\mathrm{DP}}$ was not collected or calculated in the same way for the Cimarron cases, so these are not included. For further discussion of specific differential phases, see Doviak and Zrnić (1993), Straka et al. (2000), Bringi and Chandrasekar (2001), and Jame- 

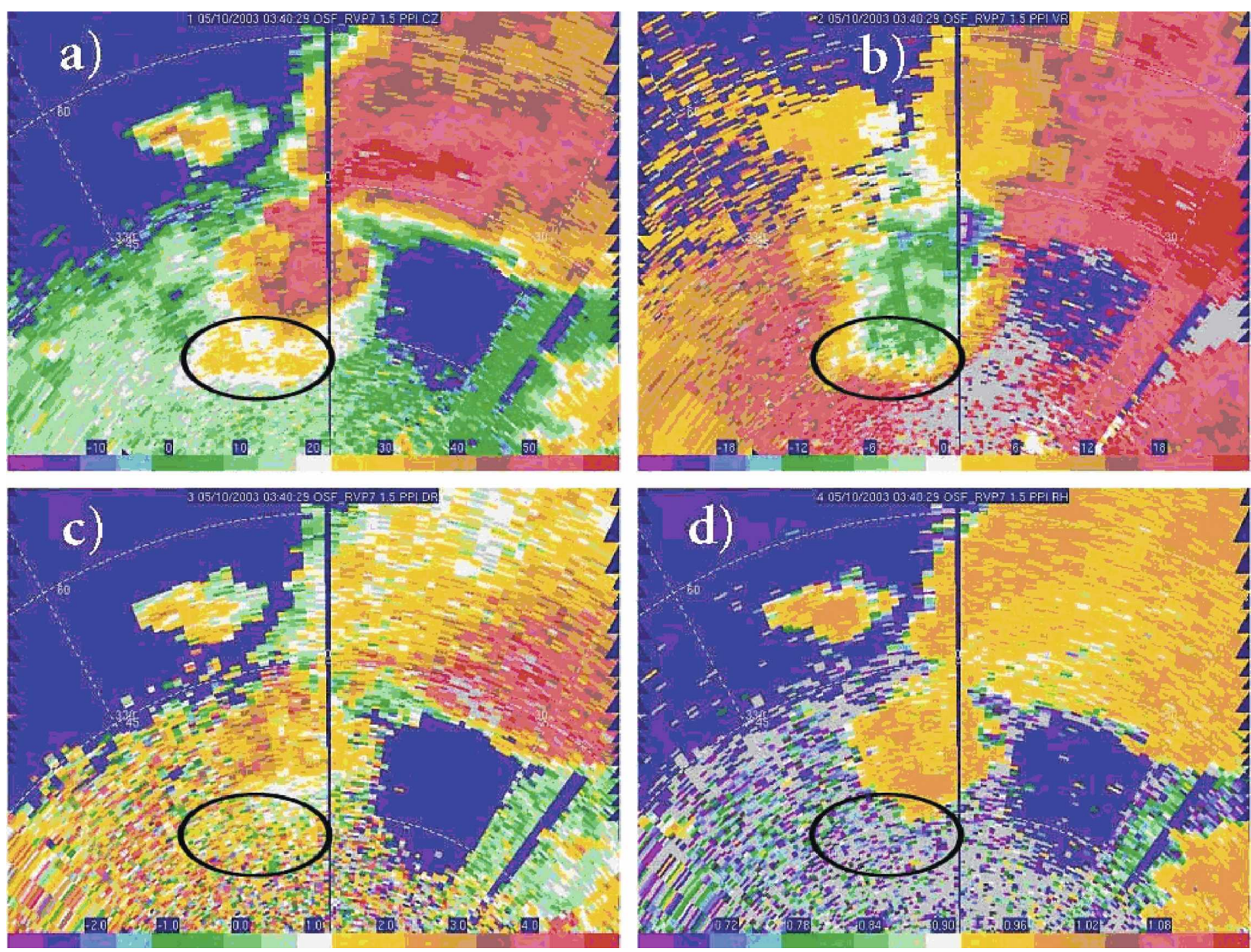

FIG. 8. Example of a supercell wake signature showing (a) reflectivity factor, (b) radial velocity, (c) differential reflectivity, and (d) correlation coefficient. Region of the wake signature is inside the black oval. In the wake signature, $Z_{\mathrm{HH}}$ is low $(<30 \mathrm{dBZ}), Z_{\mathrm{DR}}$ is intermediate $(1-2 \mathrm{~dB})$, and $\rho_{\mathrm{hv}}$ is low $(<0.7)$.

son (1985). An example of $K_{\mathrm{DP}}$ data used to construct the schematics herein is presented in Fig. 10, described below.

\section{1) Pretornado times}

At pretornado times, the supercells that were examined exhibited a similar spatial pattern of high and low values. Temporally, however, there were differences. One pretornadic case had a temporal maximum, one had a temporal minimum, and two had no discernible trend. This lack of a clear $K_{\mathrm{DP}}$ temporal signature seems characteristic of the pretornado cases examined.

Also characteristic of the pretornado times was the presence of medium $K_{\mathrm{DP}}$ (typically $0.25^{\circ}-2^{\circ} \mathrm{km}^{-1}$ ) along the back side (northwest) of the composite storm, whereas at tornado times $K_{\mathrm{DP}}$ was typically $<0.25^{\circ}$ $\mathrm{km}^{-1}$ in the same region (Figs. 9, 10). We cannot easily speculate about the meaning of this difference-per- haps it is caused by evaporation of hydrometeors due to ingestion of dry air near the tornado time, producing smaller (and more isotropic) average hydrometeors.

\section{2) Tornado times}

At tornado times, there was a temporal $K_{\mathrm{DP}}$ maximum downwind from the primary updraft in the storm's reflectivity core more often than at pretornado times. As expected, low values $\left(<0.25^{\circ} \mathrm{km}^{-1}\right)$ were located in the large region of light precipitation downwind from the main storm core (Fig. 10). High values $\left(>2^{\circ} \mathrm{km}^{-1}\right)$ typically were located in the same region as the hail shaft identified by collocated high $Z_{\mathrm{HH}}$ and low $Z_{\mathrm{DR}}$, just downwind from the primary updraft (Fig. 9). Extended regions of higher $K_{\mathrm{DP}}$ values, similar in character to the previously described reflectivity factor wings, were present more often at tornado times.

Particular care is necessary when using $K_{\mathrm{DP}}$ in the 

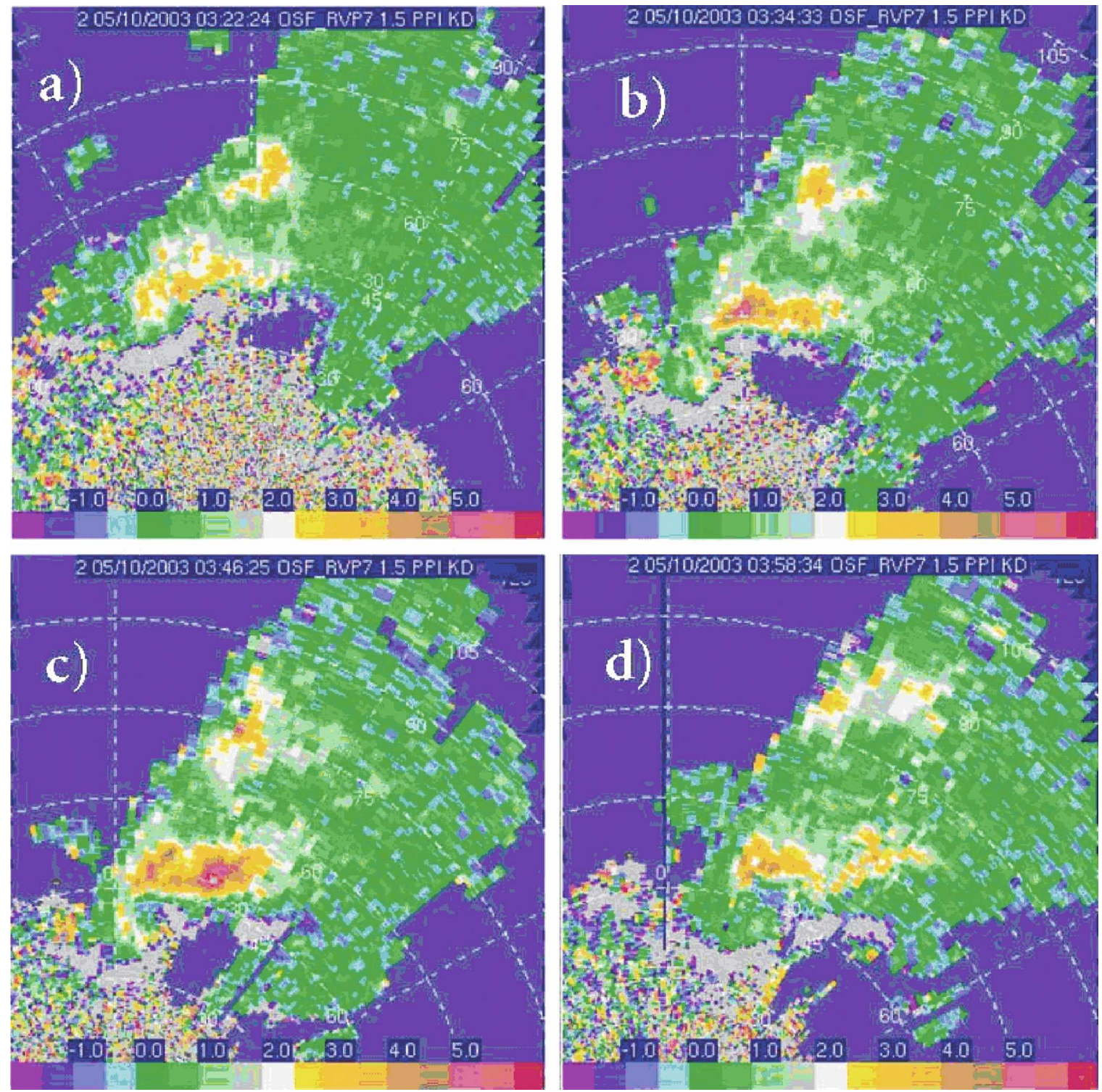

FIG. 9. As in Fig. 2, but for specific differential phase $\left(K_{\mathrm{DP}}\right)$.

echo-appendage region. Since this variable is calculated as the rate of change of $\phi_{\mathrm{DP}}$ (differential phase shift) over a given range, potential problems exist in the $K_{\mathrm{DP}}$ estimation for small ranges. If ranges that are too small are used, $K_{\mathrm{DP}}$ values will be unreliable. In the echo appendage and tornado regions, data in some range gates might be rejected because of debris contamination or only a small number of gates may be available for the calculation. Therefore, $K_{\mathrm{DP}}$ signatures potentially related to an ongoing tornado should be viewed with caution. Observations made when the tornado region is embedded within the echo appendage are more likely correct, although they are still suspect because of the effect of potentially rejected data.
In the Mie regime, scattering off particles much larger than the radar wavelength can lead to negative $K_{\text {DP }}$ values (Ryzhkov et al. 2005). Typical wavelengths for the Doppler radars used to collect these cases are on the order of $10 \mathrm{~cm}(10-11)$ and many tornado debris particles are significantly larger than this value. Values of $K_{\mathrm{DP}}<0^{\circ} \mathrm{km}^{-1}$ are therefore possibly associated with a tornado vortex in the hook-echo tip. About onehalf of the cases for which $K_{\mathrm{DP}}$ was collected during tornado times showed significantly negative values associated with the tornado vortex, while the other cases showed values near $0^{\circ} \mathrm{km}^{-1}$. No cases showed significantly positive $K_{\mathrm{DP}}$, which was prevalent in the general tornado region. Thus, the presence of an area of signifi- 


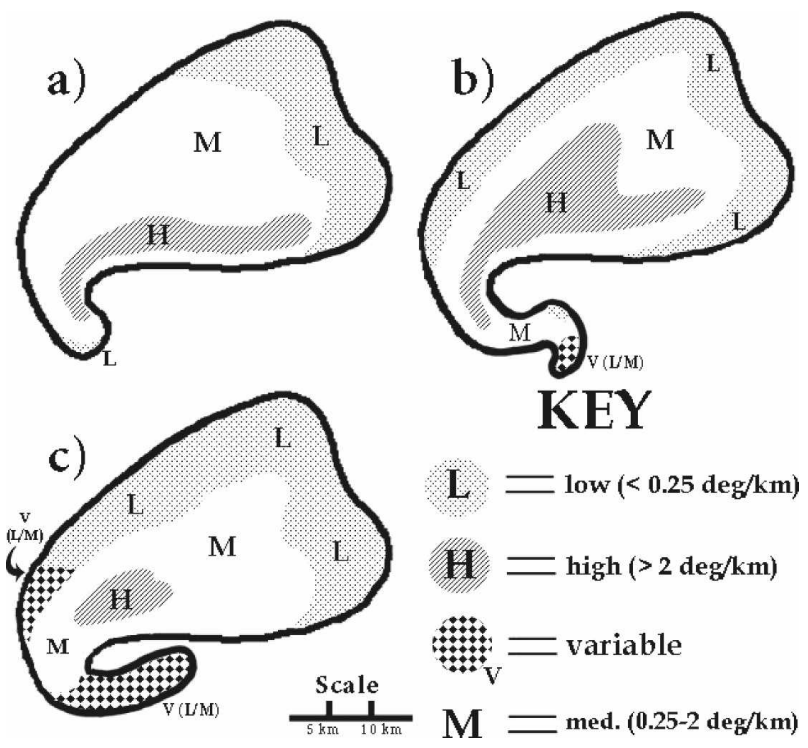

FIG. 10. As in Fig. 3, but for specific differential phase $\left(K_{\mathrm{DP}}\right)$. Stippled areas represent low values $\left(K_{\mathrm{DP}}<0.25^{\circ} \mathrm{km}^{-1}\right)$, hatched areas represent high values $\left(K_{\mathrm{DP}}>2^{\circ} \mathrm{km}^{-1}\right)$, blank areas represent intermediate values $\left(0.25^{\circ} \mathrm{km}^{-1} \leq K_{\mathrm{DP}} \leq 2^{\circ} \mathrm{km}^{-1}\right)$, and checkerboard-filled areas represent variable regions. Thick outline represents approximately the $20-\mathrm{dB} Z$ reflectivity contour.

cantly low $K_{\mathrm{DP}}$ in the supercell's tornado-favorable location seems a potentially useful diagnostic of ongoing tornado activity, although caution must be used in interpreting this signature as described above. This signature should be less in areas with low availability of larger debris particles. Tornado strength may not significantly change this effect as long as the tornado is picking up sufficiently large debris to the elevation of the radar beam. Thus the effect may become greater as the tornado approaches the radar, since the size sorting of debris should occur in the tornado vortex as lighter/ smaller debris are lofted to greater altitudes (Dowell et al. 2005). One case, because of data contamination or the presence of tornado debris, showed a well-defined $K_{\mathrm{DP}}$ minimum with a tornado nearly $100 \mathrm{~km}$ from the radar.

\section{3) Tornado DEMISE TIMES}

At tornado demise times, high $K_{\mathrm{DP}}\left(>2^{\circ} \mathrm{km}^{-1}\right)$ was typically present in a small region to the north of the primary updraft, somewhat into the main storm (Fig. $10)$. This local $K_{\mathrm{DP}}$ maximum could indicate the presence of hail and heavy rain in this area. Low $K_{\mathrm{DP}}$ $\left(<0.25^{\circ} \mathrm{km}^{-1}\right)$ was present in the large region of small drops far downwind from the primary updraft (Fig. 9). This was expected, since small drops do not attenuate radar energy as significantly as large drops and hail.
Between these regions of high and low values, intermediate values $\left(0.25-2^{\circ} \mathrm{km}^{-1}\right)$ were found.

Extended regions of high $K_{\mathrm{DP}}$ were occasionally present, although they varied from highly conspicuous to nonexistent. Their strength seemed somewhat proportional to the strength of similar extended regions of high $Z_{\mathrm{HH}}$. In the hook echo, low-to-medium $K_{\mathrm{DP}}\left(<2^{\circ}\right.$ $\mathrm{km}^{-1}$ ) was present. Well-defined and strong $K_{\mathrm{DP}}$ minimums associated with tornado debris were not typically found at tornado demise times. Otherwise, $K_{\mathrm{DP}}$ patterns seemed quite variable between the small number of available cases (Fig. 10).

\section{Conclusions and further research}

Our work is limited by the small number (seven) of available polarimetric datasets of tornadic supercells and would be much more robust if many additional cases existed. This will be possible when dual-polarimetric capability is available in a large number of WSR88D radars in the next decade. Despite this limitation, some conclusions have been reached. The reflectivity factor, $Z_{\mathrm{HH}}$, at tornado times tended to display a thinner and more cyclonically curved echo appendage and extended regions of higher reflectivity reaching northeast away from the primary updraft region. Occasionally, a stronger reflectivity gradient was present on the west side of the echo appendage, and a cyclonic-anticyclonic couplet was visible as swirls in the reflectivity field at the tip of the hook echo. A local reflectivity maximum was often located at the supercell's tornadofavorable location. At pretornado times, the $Z_{\mathrm{HH}}$ field tended to show a wider, less cyclonically curved echo appendage with a greater percentage of the echo appendage exhibiting reflectivity $>50 \mathrm{dBZ}$. At tornado demise times, the hook echo exhibited the greatest cyclonic curvature, and regions of high $Z_{\mathrm{HH}}$ often extended well south into the hook-echo region. Occasionally, a region of low $Z_{\mathrm{HH}}$ and $\rho_{\mathrm{hv}}$ with $Z_{\mathrm{DR}}$ averaging 1-2 dB was observed trailing a supercell, likely caused by residual light debris picked up in the supercell's wind field.

The differential reflectivity $Z_{\mathrm{DR}}$ showed hail shafts, implied by high $Z_{\mathrm{HH}}$ collocated with low $Z_{\mathrm{DR}}$, most often at tornado times. Highest storm values were typically located along the storm's forward flank in the primary storm inflow region. Cyclonically curved bands containing high $Z_{\mathrm{DR}}$, produced by large drops, occasionally occurred near the low-level mesocyclone at tornado times, and a $Z_{\mathrm{DR}}$ minimum frequently occurred at the tornado-favorable location. At pretornado times, $Z_{\mathrm{DR}}$ did not typically show significant differences from tornado times, although values of $1-2 \mathrm{~dB}$ tended to 
more conspicuously extend from the echo appendage to join a large area of medium values along the northwest side of the supercell. At tornado demise times, hail cores associated with regions of low $Z_{\mathrm{DR}}$ downwind from the mesocyclone were less common and conspicuous. Low $Z_{\mathrm{DR}}$, possibly associated with residual tornadic debris, was sometimes found in the hook echo.

Storm minimum $\rho_{\mathrm{hv}}$, the correlation coefficient, was frequently reached in the vicinity of a tornado at tornado times. The next-lowest correlation values (and lowest values at pretornado times) were usually located in implied hail shafts, with slightly higher values in surrounding areas of heavy rain. Low values were also typical in the storm updraft, caused by a mixture of raindrops and light debris. At all times, the highest correlation tended to occur in the light-precipitation shield well downwind from the primary storm updraft. The $\rho_{\mathrm{hv}}$ field was not significantly different between tornado and pretornado times. At tornado demise times, the $\rho_{\mathrm{hv}}$ field was characterized by high variability, but this could be a result of the small sample size.

Values of $K_{\mathrm{DP}}$, or the specific differential phase, in the storms in which it was available tended to lack any temporal trend at pretornado times, although at tornado times there typically was a temporal $K_{\mathrm{DP}}$ maximum in the storm reflectivity core. Values were relatively low in light- precipitation regions and higher in the storm reflectivity core. A pronounced region of negative values, because of Mie scattering off large debris particles, was sometimes associated with the tornado, and values near the tornado never averaged significantly higher than zero. $K_{\mathrm{DP}}$ was, as expected, found to be roughly proportional to $Z_{\mathrm{HH}}$. This proportionality was responsible for the increased frequency of extended regions of high $K_{\mathrm{DP}}$ at tornado times. The only significant spatial difference in $K_{\mathrm{DP}}$ between tornado and pretornado times was the presence of loweraverage values along the northwest side of the storm at tornado times. Tornado demise times exhibited similar patterns, although the areas of strongly negative values associated with a tornado at tornado times were not found.

We hope to run a hydrometeor classification algorithm on the southern plains low-level polarimetric data, which should allow a more thorough understanding of typical precipitation distribution and processes in these storms.

Acknowledgments. This research was supported by NSF Grants ATM 0340693 and ATM 0446509 at the University of Oklahoma. Reviews from two reviewers greatly helped the readability of this paper; Dr. Katharine M. Kanak is acknowledged for her reviews as well. We also are grateful to Drs. Dusan Zrnić, Alexander Ryzhkov, and Scott Giangrande for supplying data for our study.

\section{REFERENCES}

Brandes, E. A., 1978: Mesocyclone evolution and tornadogenesis: Some observations. Mon. Wea. Rev., 106, 995-1011.

, 1981: Finestructure of the Del City-Edmond tornadic mesocirculation. Mon. Wea. Rev., 109, 635-647.

Bringi, V. N., and V. Chandrasekar, 2001: Polarimetric Doppler Weather Radar: Principles and Applications. Cambridge University Press, $636 \mathrm{pp}$.

Brooks, H. E., 2004: On the relationship of tornado path length and width to intensity. Wea. Forecasting, 19, 310-319.

Browning, K. A., 1965: The evolution of tornadic storms. J. Atmos. Sci., 22, 664-668.

Burgess, D. B., M. A. Magsig, J. Wurman, D. C. Dowell, and Y. Richardson, 2002: Radar observations of the 3 May 1999 Oklahoma City tornado. Wea. Forecasting, 17, 456-471.

Doswell, C. A., III, and D. W. Burgess, 1993: Tornadoes and tornadic storms: A review of conceptual models. The Tornado: Its Structure, Dynamics, Prediction, and Hazards, Geophys. Monogr., Vol. 79, Amer. Geophys. Union, 161-172.

Doviak, R. J., and D. S. Zrnić, 1993: Doppler Radar and Weather Observations. Academic Press, 562 pp.

—, V. N. Bringi, A. V. Ryzhkov, A. Zahari, and D. S. Zrnić, 2000: Considerations for polarimetric upgrades to operational WSR-88D radars. J. Atmos. Oceanic Technol., 17, 257278.

, J. K. Carter, V. M. Melnikov, and D. S. Zrnić, 2002: Modifications to the research WSR-88D to obtain polarimetric data. NOAA/National Severe Storms Laboratory Rep., 49 pp.

Dowell, D. C., C. R. Alexander, J. M. Wurman, and L. J. Wicker, 2005: Centrifuging of hydrometeors and debris in tornadoes: Radar-reflectivity patterns and wind-measurement errors. Mon. Wea. Rev., 133, 1501-1524.

Forbes, G. S., 1981: On the reliability of hook echoes as tornado indicators. Mon. Wea. Rev., 109, 1457-1466.

Herzegh, P. H., and A. R. Jameson, 1992: Observing precipitation through dual-polarization radar measurements. Bull. Amer. Meteor. Soc., 73, 1365-1374.

Jameson, A. R., 1985: Microphysical interpretation of multiparameter radar measurements in rain. Part III: Interpretation and measurement of propagation differential phase shift between orthogonal linear polarizations. J. Atmos. Sci., 42, 607614.

, and K. V. Beard, 1982: Raindrop axial ratios. J. Appl. Meteor., 21, 257-259.

Kennedy, A., J. M. Straka, and E. N. Rasmussen, 2007: A statistical study of the association of DRCs with supercells and tornadoes. Wea. Forecasting, 22, 1191-1199.

Lemon, L. R., 1977: New severe thunderstorm radar identification techniques and warning criteria: A preliminary report. NOAA Tech. Memo. NWS NSSFC-1, TDU, NSSFC, 60 pp. [NTIS PB-273049].

, and C. A. Doswell III, 1979: Severe thunderstorm evolution and mesocyclone structure as related to tornadogenesis. Mon. Wea. Rev., 107, 1184-1197. 
Markowski, P. M., 2002: Hook echoes and rear-flank downdrafts: A review. Mon. Wea. Rev., 130, 852-876.

Moller, A. R., C. A. Doswell III, M. P. Foster, and G. R. Woodall, 1994: The operational recognition of supercell thunderstorm environments and storm structures. Wea. Forecasting, 9, 327347.

Rasmussen, E. N., and J. M. Straka, 1998: Variations in supercell morphology. Part I: Observations of the role of upper-level storm-relative flow. Mon. Wea. Rev., 126, 2406-2421.

$\longrightarrow,-$ M. S. Gilmore, R. Davies-Jones, 2006: A preliminary survey of rear-flank descending reflectivity cores in supercell storms. Wea. Forecasting, 21, 923-938.

Ryzhkov, A. V., T. J. Schuur, D. W. Burgess, P. L. Heinselman,
S. E. Giangrande, and D. S. Zrnić, 2005: Polarimetric tornado detection. J. Appl. Meteor., 44, 557-570.

Straka, J. M., 1996: Hydrometeor fields in a supercell storm as deduced from dual-polarization radar. Preprints, 18th Conf. on Severe Local Storms, San Francisco, CA, Amer. Meteor. Soc., 551-554.

- D. S. Zrnić, and A. V. Ryzhkov, 2000: Bulk hydrometeor classification and quantification using polarimetric radar data: Synthesis of relations. J. Appl. Meteor., 39, 1341-1372.

Zahrai, A., and D. S. Zrnić, 1993: The 10-cm wavelength polarimetric weather radar at NOAA's National Severe Storms Laboratory. J. Atmos. Oceanic Technol., 10, 649-662.

Zrnić, D. S., and A. V. Ryzhkov, 1999: Polarimetry for weather surveillance radars. Bull. Amer. Meteor. Soc., 80, 389-406. 